\title{
Critical Tourism: Assessing Snow-Based Practice in Finnish Lapland
}

\author{
Ayonghe Akonwi Nebasifu ${ }^{1}$, Francisco Cuogo ${ }^{2}$ \\ ${ }^{1}$ Doctor of Social Science Candidate and Researcher (Environmental Sociology), Faculty of Social \\ Sciences, University of Lapland \\ ${ }^{2}$ Member of Center for Research in Political Science, School of Economics and Management, \\ University of Minho
}

\begin{abstract}
Touring, traveling, or moving from one place to another for purpose of business, leisure, either locally or internationally, is known as tourism. In many countries, tourism forms an integral part of economic development through job creation, infrastructural investments, and income provision. One of the root causes for global tourism growth has been the industrial revolution in Great Britain around the $19^{\text {th }}$ century. This was characterized by a transition from hand production to use of machinery, including improved steam and water power, emergence of textile industry, new modes of iron production, which all became known as factory system. Entrepreneurship and consumerism served as driving forces for the industrial revolution which then expanded around the world. By the $20^{\text {th }}$ century, the movement of people across regions enhanced following improvements in transportation. However, the revolution also meant an increase demand for workers in factories.

Apart from industrial work, leisure accounted for movement of people during breaks from work. Although mass movement may result to income growth, it equally raises pertinent questions of how environments are constructed to suit the needs of people arriving, what kind of threats emerge from such destinations and perhaps what can be done to address such problems? Thus, this paper uses critical tourism to seek an understanding of tourism from different perspectives which address the potentials and threats in tourism. Using the case of Finnish Lapland, our observations show that snow is essential to boosting tourism. However, habits towards climate change are a threat to sustaining snow tourism in the region. The paper then proposes economic diversification as a way forward.
\end{abstract}

Keywords: Snow tourism, Finnish Lapland, Economic diversification

\section{INTRODUCTION}

Generally thinking, tourism is one of those economic practices which serve as a developmental tool in many nation states around the globe. This phenomenon can be supported based on infrastructural investment, job creation, income provision, and marketing. Back in the $18^{\text {th }}$ and $19^{\text {th }}$ century with the growth of the Industrial revolution in Great Britain, improvements in the modes of production from hand-use to machine-centered approaches became more prominent. As a result, the factory system rose with improvements in use of steam power, water power, and emergence of textile industry. In addition, the means of transportation of both people and goods improved. In essence, this meant an enhancement of trade, increase in movement of people across regions, increase in demand for workers, increasing demand for goods and services, and literally an increase in population growth.

Thus, destinations are either filled with attractive opportunities for work, business, trade, or accommodation. In some cases, leisure becomes embedded in such destinations with workers needing work-free time for relaxation and other activities. These practices are synonymous to what is known today as tourism. An increase in mass movement could have both positive and negative implications depending on a context. For instance, where in coming visitors bring money into a destination, and on the other hand where natural systems are damaged by profit-centered incentives as highlighted in past publications (See: Krippendorf, 2009). There is therefore a need to address tourism in a critical way finding new possibilities to sustain destinations without jeopardizing the host culture and natural systems. Both Richards and Wilson (2007) suggest creative tourism as a suitable option that targets sustainability through diversified strategies. 
In this paper, we use the concept of critical tourism as a method for addressing tourism practice from several dimensions while taking into consideration strengths, setbacks, and possible solutions. We seek to answer the questions of: what potential tourism offers to a destination; what kind of threats tourism faces; and what ideas could be considered for a way forward. These questions are addressed using the case of snow-based tourism in Finnish Lapland, where creativity in snow and the use of strategic policy are crucial to tourism growth. However, habits towards climate change pose future possibilities for hindering tourism growth. Our conclusive suggestion highlights applicable ways of economic diversification as a possible remedy to this problem, as will be discussed in subsequent paragraphs.

\section{THEORETICAL BACKGROUND: INDUSTRIALIZED INFLUENCE ON MASS TOURISM}

The rise of industrialization in the 18th century brought about changes in various spheres of the society, affecting political, economic, social and cultural structures. Tourism, for instance, suffered from consequences of production and consumption in society. Human beings abandoned subsistence agriculture in rural areas in favor of migration to cities in response to industrial demand. New dynamics to daily life gradually emerged in cities such as the determination of work time and free time (Gee and Fayos-Solá, 2003). Given that free time was the time not worked for, there was thus a mass movement of workers who sought leisure activities. The tourist activity then arouse as workers seek refuge from their work routines in other places that gave them possibility to rest or to know new places and regions. This period led to profound economic and social changes in society with structural transformations in urban planning. For instance, easing of human displacement and increasing supply of raw materials for industries through faster means of transportation.

By the $20^{\text {th }}$ century, living conditions and lifestyles of people did improve economically and socially, while posing problems to the environment. For example the opening of new roads, consumption of natural resources, emission of gaseous pollutants, and exploitation of wood for steam engines in factories. Consequently, environmental damages became prominent. Also, practices to maximize exploitation of resources, maximizing profits, large-scale production, marketing with the masses, standardizing schedules, and customs, which were embedded in the production and style of the industrial era, became part of mass tourism. According to Krippendorf (2009: 26), the effect of mass tourism involves a cyclical condition that repeats in an endless and clearly linked to the context of the industrial age. This implied a growth cycle: from more production which provides more labor; more labor which provides more revenue; more revenue that allows for more consumption; and more consumption that needs more production.

Due to environmental problems emerging from mass tourism, ideas gradually built up to awaken humanity on the need for sustainable behavior in society, which greatly impacted on tourism activity. This has led to development of creative tourism, which emphasizes on the proximity of tourism with local culture and the valorization of tourism sustainability. For Richards and Wilson (2007: 1) tourism destinations try to distinguish themselves from their increasingly numerous competitors who then turn to culture as a means of distinction, and culture being linked to tourism. This condition has contributed to a more segmented tourism practice that attempts, in essence, to develop a tourism activity with quality and sustainability, and not with a view to the unbridled amount through mass exploration. Richards and Wilson (2007: 110) point out that the sustainability of tourism "could thus be seen in this light as a coordination game played by actors with different strategic horizons". Therefore, strategies to sustainability in the field of cultural tourism will depend on two key points;

- Creating emotive links between local products and visitors, so that cultural empathy is established, leading to higher resilience level of the tourism development process amidst external shocks and internal market transformations.

- And maintaining variety and diversity within a destination in the face of the standardizing pressure of the global tourist market.

\section{Methodological Approach And Study Aim}

A review of web-based texts and critical tourism approach is applied to assess snow-based practices of tourism in Finnish Lapland. The chosen site represents an example of creative tourism which focuses on product quality, promoting sustainable practices, while maintaining local culture. For several decades, snow has been an inherent part of local culture manifested through practices of 
traditional ice fishing, and modes of transportation such as; snowmobiling, dog-sledding, snowshoeing, traditional cross-country skiing, reindeer sleigh rides, and tobogganing. These have gradually been incorporated into the tourism sector. Using snow as essential material in tourism, promotes environmental sustainability due to its ecological value of solidifying and melting without causing pollution to the environment. Therefore, our study aims to understand what policy is used for tourism in the region, how the site is constructed to suit visitors, what kinds of threats affect tourism, and what can be done to address related problems.

\section{CASE STUdy: SNOW TOURISM In FinNiSh LAPLAND}

Finnish Lapland experiences a winter season filled with snowfall and accumulation lasting 5-7 months annually. About half of annual precipitation 600 millimeters $(\mathrm{mm})$, falls as snow in Lapland (Finnish Meteorological Institute, 2017) making the local culture snow-oriented seasonally. This provides an opportunity for creative tourism in the region. Since the 1990s, tourism has arguably been the major income contributor to Finnish Lapland (Osmund \& Sunday, 2010). It accounts for an estimated annual tourism income of 600 million Euros and an annual regional employment of up to 5000 jobs (Rahman, 2014). Following this potential, the Finnish Ministry of Employment and the Economy then established the policy of Strategic Planning by the early $21^{\text {st }}$ century with one of its aims at internationalizing trade in tourism, attracting foreign investments, while promoting local culture, product quality, and sustainability at regional level. Thus, the Regional Council of Lapland then operated regionally based on strategic planning of tourism activities by various stakeholders in Finnish Lapland. So far, three sub strategies have been implemented based on joined agreement, implementation, and revision over time (Luiro, 2015; Lapland-Vitality for Life, 2013). These include: tourism strategy 2003-2006 which targeted internationalizing tourism trade; tourism strategy 20072010 promoting infrastructure, research, image marketing, and sustainability in tourism; and tourism strategy 2020 enhancing quality of winter and snow packages.

\subsection{Potential Trends}

So far, reports have shown that, snow is an attractive component of tourism in Finnish Lapland. This is supported by the increasing number of visitors in the region during the winter season where snow is available. For instance, in 2006, the region recorded 5\% average annual increase in overnight stay of visitors; including 2.1 million overnights of which $40 \%$ were foreign visitors. Most foreign visitors came from France, UK, Germany, Netherlands, and Russia. Other reported markets included Norway, Italy, and Switzerland. In terms of international air passenger visitors by month, December remained considerably highest as a result of the popularity of Christmas, with cities like Kittila and Rovaniemi representing remarkably high visits (Lapland-Vitality for Life, 2013). Furthermore, between the years 2000 and 2014, a significant increase in overnight stay by visitors was recorded. In general, up to 2.3 million stays in 2014 compared to around 1.6 million stays in 2000 (Luiro, 2015). These observations illustrate a great potential for tourism growth in the region.

\subsection{Site Construct: Snow Products}

One crucial aspect of creative tourism is to promote local culture by enhancing product quality and sustainability. One example is in Finnish Lapland where snow is a core material to building infrastructure, promoting qualities of ecology and sustainability, while maintaining local culture. This is observed in touristic attractions like hotels and sport facilities. Snow in particular is depicted as ecological and sustainable due to its ability to solidify in low winter temperatures of below 0 degree Celsius, while allowed to freely melt in warmer temperatures without any fundamental damage to the environment. Three example sites include; the Arctic Snow Hotel, Levi Ski Resort, and Kemi Snow Castle.

\subsubsection{Arctic Snow Hotel Rovaniemi}

Created in 2008, the 74-bed hospitality complex was entirely built with snow. Annually, a new Arctic Snow Hotel is built starting in late October or early November with ice collected from Lehtojarvi Lake and runs till March or April when the snow is left to melt onto the ground, making it of ecological quality (Finland Times, 2016). Other materials were later incorporated to the structure. The temperature within the hotel remains between 0 and -5 degrees Celsius, with the walls helping to insulate the temperature during extremely cold weather conditions of up to -30 degrees Celsius. The hotel is said to receive foreign guests who make up more than 95\% of total visitors (Finland Times, 2016). Services incorporated to its snow package include; snowshoe hiking, snow sauna, hot tub, and ice fishing at Lake Lehtojarvi. 


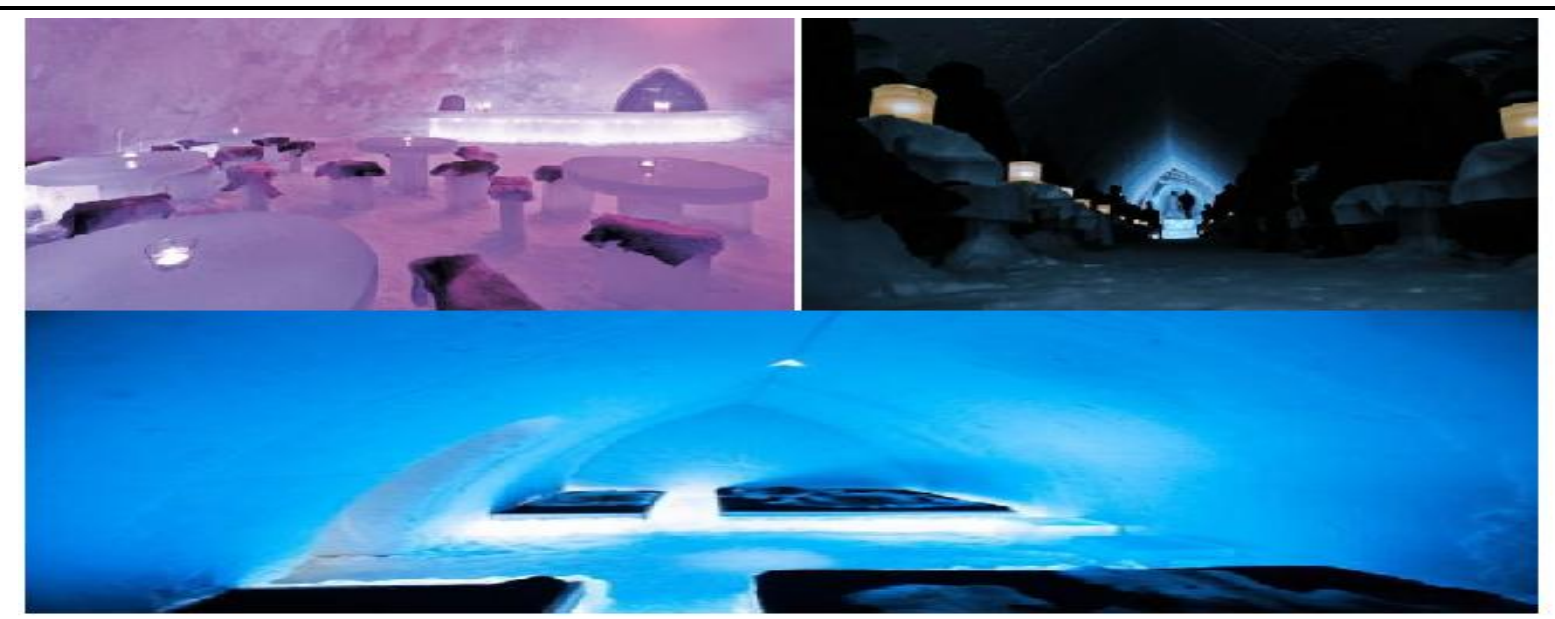

Ice bar, Ice Chapel, and family room (Arctic Snow Hotel, 2017)

\subsubsection{Levi Ski Resort}

Created in 1964, Levi Ski Resort gradually became known as Finland's fastest growing ski area in the country. Skiing season lasts October to May as the longest in the country. The upper slopes contain accumulated snow of $85 \mathrm{~cm}$ deep and $80 \mathrm{~cm}$ for lower slopes (Snow Magazine, 2016). Nearly 50 slopes consisting of more than 25 lifts (operating 10 am to $8 \mathrm{pm}$ ) with a capacity to uplift more than 27,000 people per hour; cross-country tracks of $230 \mathrm{~km}$ of which $28 \mathrm{~km}$ are illuminated for night skiing; a snow park which constitutes jumps, boxes, rails, and hits. In 2004, the first ever Ladies World Cup event in Finland was hosted by the Levi Ski Resort and followed by the 2006 hosting of the Men's World Cup which upgraded the resort's status to World Cup standards.
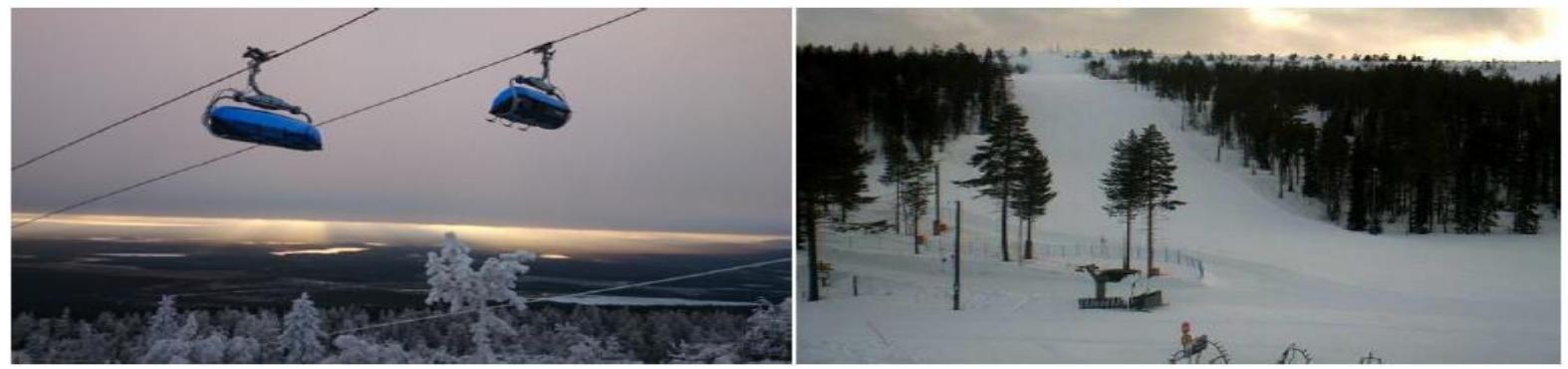

Ski lifts and Pistes (Levi Ski Resort, 2017)

\subsubsection{Kemi Snow Castle}

The Castle was created in 1995 as a gift from the United Nations International Children's Emergency Fund (UNICEF). Since then, a new Castle is built in the winter month of January and left to melt away in the spring of every year. The castle is between 13,000-20,000 square meters high structure to look as a majestic fairytale world during the winter. The Castle walls are over 12 feet high, made of ice, and lit with colourful lights. Kemi Snow Castle consists of a chapel, an art gallery, and hotel which offer a chill experience, wedding opportunities, and sculpturing experiences for many visiting artists and tourists around the globe each year. Additional features include a restaurant, a themed room, and slippery slides (Atlas Obscura, 2017).

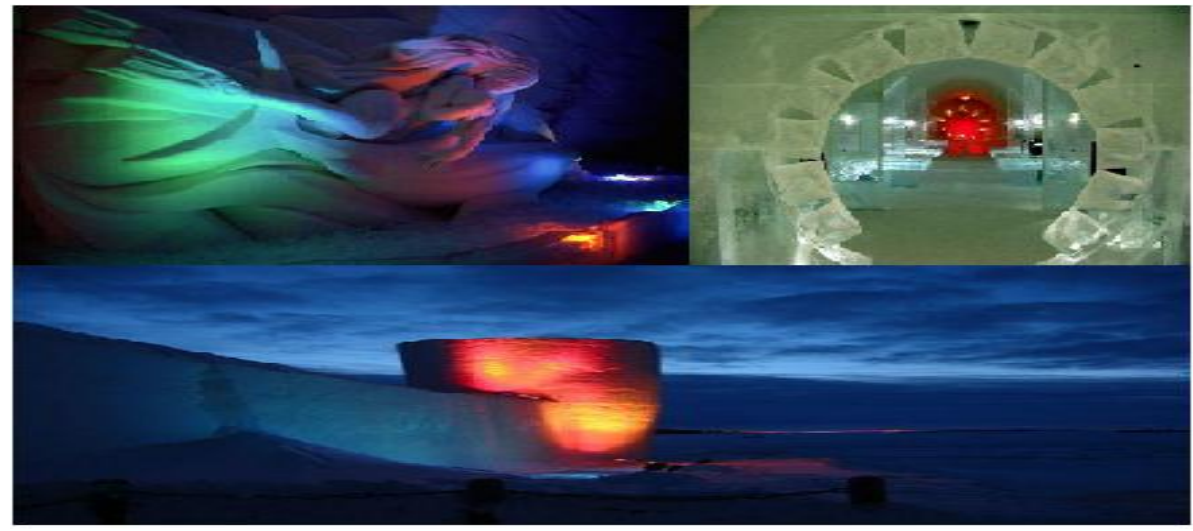

Snow Castle, Kemi (Atlas Obscura, 2017) 


\section{A Major Challenge FaCing SNOW TOURiSM in FinniSh LAPLAND}

Apart from competition arising from other ddestinations of Christmas tourism such as Iceland, Norway, and Sweden, at the detriment of Finnish Lapland, one widely discussed problem is the threat posed by climate change and the challenge of ensuring supply of snow every winter season. Thus, raising fears about a no-snow scenario in future. A table by Tervo-Kankare et al (2012) illustrate the habits of foreign tourists in the regional capital of Finnish Lapland, Rovaniemi, towards climate change and its impact on snow availability. This is based on a survey research conducted in December 2007 at Rovaniemi airport.

Table1. Respondent's opinions about the attractiveness of Rovaniemi's in response to changing conditions (Tervo-Kankare et al, 2012: 18).

\begin{tabular}{lrr}
\hline Questions & Yes & No \\
\hline $\begin{array}{l}\text { If the snow season did not start until January would you visit Rovaniemi at } \\
\text { that time? }(N=236)\end{array}$ & $42 \%$ & $58 \%$ \\
If the snow reliability was secured would you be willing to pay more? & $58 \%$ & $42 \%$ \\
$\quad(N=236)$ & & \\
Would you have decided to travel to Rovaniemi & $23 \%$ & $77 \%$ \\
$\quad$ if there was no snow? $(N=236)$ & $37 \%$ & $63 \%$ \\
$\quad$ if snow reliability was poor? $(N=238)$ & $41 \%$ & $59 \%$ \\
$\quad$ if rather than any natural snow most snow was produced with & & \\
$\quad$ snowmaking facilities? $(N=239)$ & $47 \%$ & $53 \%$ \\
if there were more people? $(N=235)$ & $79 \%$ & $21 \%$ \\
if there were less people? $(N=232)$ & &
\end{tabular}

The table above represents opinions of 246 tourists including British, Irish, French, Spanish, Cypriot, Swiss, and other Europeans in Rovaniemi, with the aim to assess human respond habits to a possible "No-Snow Scenario" in future. Findings showed that Christmas tourists in Rovaniemi react negatively to the estimated changes and various adaptation mechanisms planned for the tourism industry.

Furthermore, Rovaniemi has been predicted to have a snowless Christmas with less than $10 \mathrm{~mm}$ snow cover becoming more frequent in every fourth Christmas by the late $20^{\text {th }}$ century. There are fears among tourists that by the year 2100, winters in Finnish Lapland will be just about $5{ }^{\circ} \mathrm{C}$ when compared to baseline climatic conditions in 1961-1990. It's expected that the snow season will shorten by a week every 15 years (Tervo-Kankare et al, 2012).

\section{Conclusive Remarks and Proposals For Progress}

Amidst the difficulty of fears of climate change facing snow tourism in Finnish Lapland, other aspects in the region that attract tourists include silence, nature, and Northern lights. Therefore, one possible way for progress is through economic diversification in tourism. This entails including other economic versions of attractive products and services. In addition, image marketing of tourism could also target the summer season which offers opportunities for many local and cultural events in the region. Possible ways of achieving economic diversification include; adaptation and re-branding.

Santa Park in Rovaniemi for instance indicated that 50,000 snowballs are being stored in reserve for a snowless winter in future (Tervo-Kankare et al, 2012). Both the Levi Ski Resort and Snow Castle Kemi have incorporated snow cannons to ensure continues supply of abundant snow for infrastructure. In terms of re-branding, the Inclusion of non-snow products in branding is worth considering. For instance, Arctic Snow Hotel in 2014 integrated the glass igloos to its snow packages. Materials like wood, plastic and metals have been added in the construction process, with over 10,000 lead lamps that light up the hotel giving it a luxurious service quality.

\section{REFERENCES}

[1] Arctic Snow Hotel (2017) Image Gallery: Arctic Snow Hotel and Glass Igloos. Available: http://arcticsnowhotel.fi/photo-gallery/

[2] Atlas Obscura (2017) Kemi Snow Castle. Available: http://www.atlasobscura.com/places/kemisnowcastle

[3] Finnish Meteorological Institute (2017) Climate Elements. Available: http://en.Ilmatieteen laitos.fi/climate-elements 
[4] Gee, C.Y., Fayos-Solá, E. (2003) International tourism: a global perspective. 2. Ed. Porto Alegre, RS: Bookman. World Tourism Organization, Madrid, Spain, pp. 1-7.

[5] Krippendorf, J. (2009) Sociology of Tourism: for a new understanding of leisure and travel. ed. São Paulo, SP: Aleph. Available: http://revistas.uexternado.edu.co/index.php/tursoc/article/ view/3720/4071

[6] Lapland-Vitality for Life (2013) An Abstract of Lapland Tourism Strategy 2007-2010. Available: http://www.lapinliitto.fi/c/document_library/get_file?folderId=21330\&name $=$ DLFE677.pdf

[7] Levi Ski Resort (2017) Skiing Pistes, Lifts and Tracks of Levi. Available: http://www.levi.fi/ en/enjoy-levi/skiing-snowboarding/pistes-tracks.html

[8] Luiro, S. (2015) Lapland Tourism Strategy 2015-2018. Regional Council of Lapland. Available: www.lapinliitto.fi/matkailu

[9] Osmund, H.A., and Sunday, J. (2010) Winter Tourism Product Development in Rovaniemi for Lapland Safaris. Thesis, School of Tourism and Hospitality, Rovaniemi University of Applied Sciences, Finland.

[10] Rahman, M.H. (2014) Tourism Development in Finland. Case Study -Tourism Development in Lapland and its Socio-economic Impacts. Thesis, Centria University of Applied Sciences, Finland.

[11] Richards, G., Wilson, J. (2007) Tourism, Creativity and Development. New York, NY: Taylor \& Francis Group.

[12] Snow Magazine (2017) Levi Finland. Available: http://www.snowmagazine.com/ski-resortguide/1010-finland/levi

Citation: Akonwi Nebasifu, Ayonghe, and Cuogo Francisco. "Critical Tourism: Assessing Snow-Based Practice In Finnish Lapland." International Journal of Research in Tourism and Hospitality (IJRTH), vol 3, no. 3, 2017, pp. 1-6. doi:http://dx.doi.org/10.20431/2455-0043.0303001.

Copyright: @ 2017 Authors. This is an open-access article distributed under the terms of the Creative Commons Attribution License, which permits unrestricted use, distribution, and reproduction in any medium, provided the original author and source are credited. 